\title{
Santos, Boaventura de Sousa, Para uma revolução democrática da justiça
}

Fábio de Sá e Silva

\section{CpenEdition}

\section{Journals}

Edição electrónica

URL: http://journals.openedition.org/rccs/765

DOI: $10.4000 /$ rccs.765

ISSN: 2182-7435

Editora

Centro de Estudos Sociais da Universidade de Coimbra

\section{Edição impressa}

Data de publição: 1 outubro 2007

Paginação: 173-176

ISSN: 0254-1106

\section{Refêrencia eletrónica}

Fábio de Sá e Silva, "Santos, Boaventura de Sousa, Para uma revolução democrática da justiça »,

Revista Crítica de Ciências Sociais [Online], 78 | 2007, posto online no dia 01 outubro 2012, consultado o 21 setembro 2020. URL : http://journals.openedition.org/rccs/765 ; DOI : https://doi.org/10.4000/ rccs. 765 


\section{Recensões}

\section{Santos, Boaventura de Sousa, Para uma revolução democrática da Justiça. São Paulo: Cortez, 2007, 120 p.}

Dentre os maiores benefícios que nós brasileiros podemos auferir da conhecida empatia que Boaventura de Sousa Santos nutre pelo país está a sua permanente disposição não só para analisar alguns dos problemas que afligem a nossa sociedade, mas também para tomar partido de lutas importantes ao fortalecimento da nossa democracia. Um exemplo notável disso ocorreu há bem pouco, quando ele esteve em Belo Horizonte para proferir uma palestra a uma platéia que não era composta por grandes nomes da ciência, mas sim pelos participantes do $6^{\circ}$ Festival do Lixo e da Cidadania, organizado pelo Movimento Nacional de Catadores de Materiais Recicláveis (MNCR).

Mas se o leitor quiser se restringir à fortuna analítica que resulta desse caloroso sentimento, uma boa recomendação é o seu mais recente livro, publicado pela Editora Cortez. Baseado numa conferência que ele proferiu em Brasília no dia 6 de Junho de 2007 a convite do ministro da Justiça, a publicação engloba uma ampla análise do nosso Judiciário junto com diversas proposições para uma Revolução Democrática da Justiça, como o título bem sugere.

Existem três questões principais que ajudam o sociólogo português a conduzir sua análise. A primeira pode ser colocada como: O que fez com que o Judiciário, que Alexander Bickel designou tempos atrás como o menos perigoso dos poderes, se tornasse um ponto tão crítico no entendimento das democracias contemporâneas? Enfrentando esse problema, o autor identifica duas importantes conexões entre direito, política e sociedade. Primeiro, ele sustenta que o Judiciário está situado no meio de uma forte contradição entre o surgimento do neoliberalismo, o crescimento das desigualdades sociais e o aumento da consciência entre os cidadãos e cidadãs do mundo em relação à injustiça que subjaz a esta condição. Noutras palavras, ele indica que vivemos num tempo no qual o inconformismo ainda persiste e, o que é mais curioso, volta e meia se traduz na luta por direitos, sobretudo quando a revolução e o socialismo parecem ter sido postos para fora da agenda política. Basta ver, por exemplo, o caso do Movimento dos Trabalhadores Rurais Sem-Terra (MST), que ele oportunamente examina. Numa fase inicial, o movimento era reticente quanto a perseguir seus objetivos no âmbito do sistema jurídico, até porque o direito parecia servir apenas para oprimi-lo. Mas com o passar do tempo, ele começa a vencer algumas lutas nos tribunais, tendo admitido o direito de fazer ocupações de terra para pressionar por avanços na reforma agrária. Essas circunstâncias ajudam a desenvolver, entre os Sem-Terras, a idéia de que afinal, "o direito é contraditório e pode ser utilizado pelas classes populares” (p. 30). A outra conexão que ele deduz está relacionada com a corrupção. Em todo o mundo, os Tribunais têm enfrentado maus momentos ao lidar com a corrupção, seja quando auxiliam no combate à corrupção, seja quando são eles próprios focos de corrupção. Mas para manter a atenção apenas no primeiro caso, o problema está em que "os tribunais não foram feitos para julgar para cima, isto é, para julgar os poderosos. Eles foram feitos para julgar os de 
baixo. As classes populares, durante muito tempo, só tiveram contacto com o sistema judicial pela via repressiva, como seus utilizadores forçados. Raramente o utilizaram como mobilizadores activos". Portanto, "no momento em que os tribunais começam a julgar para cima, em que começam a incriminar e a julgar grandes empresários ou membros da classe política, a situação muda". Acontece o que o autor designa por uma "politização do judiciário, tornando-o mais controverso, mais visível e vulnerável politicamente" (p. 22).

Nesse quadro, o autor enfrenta uma segunda questão: Por que existem tantas pressões pela reforma da justiça, especialmente em países em desenvolvimento? Novamente, ele argumenta que as causas centrais encontram-se na contradição estrutural enfrentada por essas sociedades. De um lado, existem as pressões econômicas trazidas pelo Banco Mundial, o Fundo Monetário Internacional e as agências multilaterais de apoio ao desenvolvimento. O ponto aqui é prover a circulação de capital com rapidez e previsibilidade, garantindo-se o cumprimento dos contratos e delineando-se um marco regulatório consistente para os grandes negócios. Para um exemplo de como essa racionalidade pode vitimar a oferta de serviços judiciais, Santos menciona um estudo concluindo que não menos que $81 \%$ dos casos de litigação civil em Lisboa tinham como objetivo a cobrança de pequenas dívidas e eram propostas por companhias de gás, eletricidade e telefone. Como conseqüência, o sistema como um todo acabava bloqueado para diversas outras demandas relevantes para os cidadãos, em casos como os de família, responsabilidade civil, etc. (p. 28).

Todavia, as pressões para reformas também vêm de baixo. Cidadãos organizados dispostos a lutar por uma vida melhor vão ao judiciário para reclamar por direitos, já se disse anteriormente. Mas acontece que ao fazê-lo, eles demandam um judiciário capaz de ouvi-los e entender as suas necessidades como questões de direito e não de filantropia ou caridade. Em outras palavras, demandam autoridades judiciárias que não os esmaguem "pela sua linguagem esotérica, pela sua presença arrogante, pela sua maneira cerimonial de vestir, pelos seus edifícios esmagadores, pelas suas labirínticas secretarias" (p. 31). É o caso dos "desempregados e dos trabalhadores precários, dos camponeses sem-terra, dos indígenas espoliados, das vítimas de despejos, das mulheres violentadas, das crianças e adolescentes abandonadas, dos pensionistas pobres" (p. 35). Se o ponto de vista dessas pessoas for considerado na concepção das reformas da justiça, diz Boaventura, então o resultado será uma dupla transformação: haverá maior acesso à justiça, mas o maior acesso à justiça mudará a justiça a que se tem acesso.

Isso leva a uma terceira questão: Quais seriam as características de uma reforma judicial que adotasse como um princípio de orientação o ponto de vista desses grupos marginalizados? Embora o autor transite por vários assuntos ao responder esta pergunta, existem ao menos três grandes linhas que embasam o seu argumento e que merecem ser enfatizadas.

A primeira linha passa por uma noção de direito que é plural, tanto em termos quantitativos quanto em termos qualitativos. Essa idéia surge com clareza, por exemplo, quando Boaventura discute como expandir o acesso à justiça. Ao invés de voltar os olhos apenas aos operadores formais, ele também inclui experiências populares de busca por direitos, como as "Promotoras Legais Populares" e as "Assessorias Jurídicas Universitárias", dentre outros. A primeira iniciativa é composta por mulheres que recebem educação jurídica informal e trabalham nas comunidades em defesa de outras mulheres. A última é integrada por 
estudantes de direito provendo assessoria jurídica a movimentos populares, com atenção a conflitos estruturais e uso de estratégias extremamente politizadas, no que vai muito além do serviço de varejo oferecido pelas clínicas jurídicas dos EUA ou os antigos escritórios-modelo nas faculdades brasileiras. Mas o fato é que ambas encontram-se na fronteira entre o oficial e o não-oficial, como indicativo de que $o$ direito é criado e distribuido na sociedade não apenas em diferentes espaços e tempos, mas também de diferentes maneiras, como já afirmei em outro lugar (Silva, 2007). A segunda linha refere-se a inovações institucionais. A expressão se tornou lugar comum nos debates sobre reformas judiciais, mas o autor soube desde logo atribuir-lhe um sentido particularmente engajado, como um meio para a construção de uma "justiça democrática de proximidade" (p. 59). Assim, ele parece compartilhar das conclusões a que Maureen Cain e Christine Harrington chegaram há cerca de dez anos, ao perceberem que as demandas dos espoliados não raro exigem novas formas para serem veiculadas e processadas. "A luta por regras (discursos) e a luta por instituições", diziam as autoras, "mostram-se interconectadas e intimamente conectadas com o que parecia ser o limite do direito" (1994: 02).

Com relação ao caso brasileiro, Santos advoga por algumas alternativas que já são bem conhecidas nos países do Norte, tais como a conciliação, a mediação e a justiça restaurativa. Mas também põe holofotes em dados bem particulares de nossa experiência societária, como é típico de sua “sociologia das emergências" (2004). São os exemplos da justiça comunitária, da justiça itinerante e dos juizados especiais. Como aproveitar essa diversidade para forjar um modelo de justiça e segurança mais integrado à produção da cidadania parece ser o grande desafio, mas a sugestão de Santos é de que isso demandará novas atitudes por parte de quem atua na área. Isso conduz à última linha de sua argumentação, que se refere à cultura jurídica e à formação de operadores do direito. Neste ponto, ele defende profundas mudanças no ensino jurídico, tanto ao nível das Faculdades quanto ao nível das Escolas de Formação Continuada vinculadas às profissões jurídicas. Mas que espécies de mudança viriam a satisfazê-lo? Certamente, mudanças que ajudassem a dissolver as crenças dominantes sobre o direito nas quais ele aparece como algo autônomo, que só é excepcionalmente mobilizado na dinâmica da vida em sociedade e que se realiza plenamente no âmbito do processo judicial.

Exemplos concretos de como esse imaginário opera são dramáticos, e os seus efeitos já suficientemente negativos podem ser potencializados ainda mais pela exposição dos Tribunais à grande mídia. A maioria dos juízes assume o mito da democracia racial, criando uma grande barreira ao avanço dos direitos civis no país (p. 67). Em outro plano, juízes criminais com uma mentalidade na qual a prisão é a melhor resposta ao crime raramente condenam réus a qualquer das chamadas penas alternativas, apesar da terrível realidade das prisões brasileiras. Não parece por acaso que, recentemente, os Ministérios da Educação e da Justiça decidiram apoiar experiências inovadoras nas Faculdades de Direito, no âmbito do projeto "Reconhecer". Neste ponto, a constituição de uma zona de pesquisa-ação que à falta de melhor alternativa tenho designado por uma "Metodologia do Ensino do Direito" (Silva, 2007) pode ter muito a contribuir. Novas Diretrizes Curriculares para os Cursos Jurídicos foram lançadas a partir de um amplo movimento de reforma desencadeado nos anos 90 e há ricas iniciativas que se constituem ou se fortalecem com base 
nas possibilidades aí inauguradas, como é o caso de "O Direito Achado na Rua" na Universidade de Brasília ou do "Grupo Interdisciplinar de Trabalho e Estudos Criminais-Penitenciários" na Universidade Católica de Pelotas. Mas apesar do bom trabalho que fazem ao relacionar o ensino jurídico com os desafios contemporâneos para a reinvenção da emancipação social, muitas destas práticas permanecem carentes de maior sistematização.

Em suma, este livro oferece uma provocativa contribuição para o campo e pode ser proveitoso para mais de um público. Brasileiros e brasileiras que lidam com o sistema, como atores ou usuários, encontrarão na publicação uma bela e progressista agenda. Em que medida ela pode ser ou será implementada, isso é algo que dependerá da maturidade da nossa democracia. Ao mesmo tempo, o livro ainda pode iluminar alguns debates em andamento no Norte. Pode-se achar curioso, por exemplo, que uma revolução democrática da justiça esteja a ser concebida em algum lugar enquanto nos Estados Unidos há muito ceticismo sobre a busca por direitos nos Tribunais. Frente a conservadorismos políticos e judiciários e ao fortalecimento do capitalismo corporativo, até mesmo a bem-estabelecida tradição do "public interest law" enfrenta um destino incerto (ver, por exemplo, Cummings e Eagly 2006; Trubek 2005). Nesse sentido, não seriam os Tribunais a coisa errada para se pensar a respeito?

De certo, Santos não é ingênuo. Ele sabe que "a revolução democrática da Justiça nunca poderá ocorrer sem a revolução democrática do Estado e da Sociedade", mas cumpre a importante tarefa de nos recordar que "esta tão pouco será possível sem a revolução democrática da justiça”. Por isso, conclui: "É pertinente perguntar pela contribuição do sistema judicial para uma tal revolução democrática mais ampla. A contribuição é possível mas sob condição de o sistema judicial passar a ser outro, muito diferente daquele que conhecemos".

\section{Referências bibliográficas}

Cain, Maureen; Harrington, Christine (1994), "Introduction", in M. Cain; C. Harington (orgs.), Lawyers in a postmodern world: translation and transgression. New York: NYU Press.

Cummings, Scott; Eagly, Ingrid (2006), “After Public Interest Law”, Northwestern University Law Review, 100(3), 1251-95.

Santos, Boaventura de Sousa (2004), "Para uma sociologia das ausências e uma sociologia das emergências", in B. S. Santos (org.), Conbecimento prudente para uma vida decente: 'um discurso sobre as Ciências' revisitado. São Paulo: Cortez, 777-821.

Silva, Fabio Costa Morais Sá e (2007), Ensino jurídico. A descoberta de novos saberes para a democratização do direito e da sociedade. Porto Alegre: Sergio Antonio Fabris Editor.

Trubek, Louise (2005), "Crossing Boundaries: Legal Education and the Challenge of the 'New Public Interest Law'”, Wisconsin Law Review, 2.

Fabio de Sá e Silva 